\title{
Geautomatiseerde evaluatie van juridische vertaling tussen kleinere talen
}

\section{Automatic evaluation of legal translation between languages of lesser diffusion}

Milan Potočár, Benjamin Bossaert

\begin{abstract}
In this contribution, problems of assessing legal translations and its objectivity will be discussed. Objective assessment proves to be a difficult issue in particular when assessing rare language combinations, such as Slovak - Dutch or Dutch - Czech, since not so much competent translators and assessors are available in these combinations. In this context, we propose a method based on the PIE method and Segers' and Kockaert's benchmark method, which, by means of a consensus ratio, can significantly increase the objectivity of text assessments.
\end{abstract}

\section{Keywords}

Legal translation, evaluation, assessment, languages of lesser diffusion, consensus ratio, benchmarks, objectivity 


\section{Inleiding}

De voorbije jaren werd er op het vlak van juridisch vertalen naar en van het Slowaaks een toenemende vraag naar kwaliteitscriteria bij het toetsen van de beëdigde tolken en vertalers waargenomen. Aangezien alle EU-lidstaten als een gevolg van de EU-richtlijn 2010/64 / EU (vgl. Orlando 2015: 5) verplicht zijn om de gerechtelijke procedures via adequate vertaal- tolkdienst in de eigen taal te garanderen, stijgt hierbij de nood aan een voldoende aantal vertalers en tolken voornamelijk bij weinig verspreide taalcombinaties. In de context van kleinere talen biedt de norm EN-15038 alleen algemeen geformuleerde eisen aan de vertaalde teksten, die bij een concentratie aan de kleinere talen door de variërende graad van equivalentie geen duidelijk vastgelegde criteria vormen, waarmee vertalers zich bij het voorbereidingsproces zouden kunnen oriënteren.

Omdat er tekortkomingen vastgesteld werden wat betreft de theoretische basis in de vertalersopleiding, namen de Comenius Universiteit te Bratislava en de Matej Bel Universiteit in Banská Bystrica het initiatief om het project TransIus - Van Conventies naar normen in de vertaling binnen het juridisch discours te lanceren, met als hoofddoel de gangbare juridisch conventies en normen, zoals die voorkomen in taalcombinaties van minder verspreide talen, te gieten in een sluitende theoretische basis. Deze theorie zou dan geformuleerd worden in samenhang met de conventies en normen binnen de specifieke taalsituaties met betrekking tot de Slowaakse wetgeving en juridische vertaalopdrachten in Slowakije. (Štefková 2013a: 124-127). Als een deel van dit project, proberen we met het hier gepresenteerde onderzoek om de kwaliteitsverwachtingen van de toelatingsexamens voor de beëdigde vertalers te definiëren. In dit artikel onderzoeken we de mogelijkheden om beoordeling van vertalingen effectiever en objectiever te maken. Dat doen we met een deels geautomatiseerd proces, namelijk door de statistische methode PIE toe te passen. We analyseren hiervoor bij het meten van tekstkwaliteit dan referentiepunten in vertalingen. Deze methode wordt verder in het artikel besproken.

\section{De onbereikbaarheid van objectieve evaluatie}

Uiteraard moet de beoordeling van een vertaling objectief zijn. Maar dat lukt nooit helemaal. Iedere beoordeling is wel in zekere mate subjectief. Het gaat erom de beoordeling toch zo objectief mogelijk te laten zijn, zodat de resultaten door niemand betwijfeld kunnen worden (Štefková 2013b: 21-23). De belangrijkste reden voor deze veralgemening is dat bijna bij alle vormen van tekstevaluatie niet alleen feiten en beslissende elementen zijn opgenomen, maar ook het kwaliteitspatroon van elke beoordelaar, dat wordt beïnvloed door individuele voorkeuren, waarden of zelfs vooroordelen. Zelfs een eventuele strikte focus op feitelijke en onbetwistbare aspecten zijn geen garantie voor objectiviteit, omdat in dit geval concrete afgewogen reflectie of een uitdrukking van belangrijkheid van een fout (gewogen coëfficiënt) niet altijd een evident resultaat oplevert.

Hoewel tekstuele en extralinguale aspecten bij de beoordeling van elke tekstsoort nauw met elkaar samenhangen, is het een belangrijke voorwaarde van objectiviteit om 
zich op één bepaald meetbaar aspect te concentreren, wat in het geval van de toelatingsexamens hier over gerechtsvertalen de tekst als product is, zonder een expliciete noodzaak om de vertaalomstandigheden of de achtergrond van de vertaler te kennen. Het niveau van de competentie van de vertaler kan dan alleen secundair worden beoordeeld, namelijk op basis van de aannamen van de tekstperceptie Ondanks deze beperkte focus kan de vertaalde juridische tekst niet alleen worden begrepen als een taalkundige overdracht (vgl. Catford 1978), maar eerder als de productieve output van de veel complexere onzichtbare competentie-gerelateerde disciplines (vgl. Prieto Ramos, 2011: 15-16). Vanuit het perspectief van de tekstevaluatie, kunnen we immers moeilijk vaststellen of de vertaler onder stress stond, en of het hier om een student of een ervaren vertaler zou gaan, maar de externe factoren kunnen alleen dienen om de grenzen van een aanvaardbaar aantal fouten en andere geëiste kwaliteiten in te stellen.

De beoordeling van de toelatingsexamens wordt in de context van juridische vertalingen in Slowakije voornamelijk beïnvloed door het kleine aantal kandidaten evenals de beschikbare gecertificeerde vertalers. (www1 2017) De vertaalopdrachten worden dan vaak zonder helder gedefinieerde regels, met nauwelijks gestandaardiseerde vertaaloplossingen en in cultureel onbekende communicatie uitgevoerd. Dit resulteert in een laag niveau van terminologische equivalentie en soms dubbelzinnigheid van de specifieke vertaaloplossingen voor de problemen die voortkomen uit de verschillen tussen de rechtssystemen van de bron- en de doeltaal (Štefková 2013a: 124-127). Als we onder vertaling een overgang tussen twee systemen verstaan, kunnen we bij de formulering van kwaliteitscriteria van vertalingen alleen van een approximatieve aanpak (aanpak bij benadering) spreken, die met een zekere graad van niet-equivalentie en onvertaalbaarheid rekening houdt (Štefková 2013b: 24). Daardoor hebben ook de al geformuleerde acceptatiecriteria van de juridische vertalers (vgl. EULITA. 2013; Hertog et al. 2001) vaak alleen een functie van een richtlijn. De eindbeslissing of een vertaling al dan niet acceptabel is en ook het selecteren van geschikte beoordelingsvorm ligt bij de beoordelingscommissie, waardoor de objectieve benadering betwijfeld kan worden (Orlando 2015: 16). Omdat de vertaler in de minder frequente talencombinaties niet over voldoende middelen beschikt, kan het afbakenen van de acceptatiedrempel dan ofwel heel analytisch en langdurig of via tamelijk ondoorzichtige interdisciplinaire communicatie vastgelegd worden (Hrehovčík 2006: 24-26; Štefková 2013a: 22). Vanuit het perspectief van de evaluatiemethodologie kan deze procedure echter leiden tot overlappingen tussen onderwerpen, omdat de focus vanuit de tekstperceptie naar de competentiebeoordeling verschuift. De bedoeling van onze voorgestelde modelevaluatie is dan de analytische kwaliteitsbeoordeling efficiënter en transparanter te maken, zodat de tekstuele zwaartepunten snel en op een geüniformeerde manier verzameld en behandeld kunnen worden. 


\section{Objectivering en effectiviteit binnen het evaluatieproces}

Elk evaluatieproces kan in principe in drie hoofdfasen worden onderverdeeld: 1. selectie van geëvalueerde aspecten 2. bepaling van de aanvaardbaarheid 3. gegevensverwerking in een overzichtelijke samenvatting. Het algemene kenmerk van elke methode is dat de voorbereidende stap de startfase is, die beslist: "wat belangrijk is" en "hoe dat belangrijk is" (Potočár 2017: 237). Afgezien van de mogelijke externe factoren, die hier een rol spelen, hebben de duidelijk gedefinieerde kernaspecten van de geëvalueerde tekst in de eerste fase ook een enorme impact op de verdere stappen, waarbij de vastgestelde beoordelingsfocus wordt uitgevoerd. Door deze afbakening baseren evaluatiemodellen zich op bepaalde prioriteiten, die meestal subjectief beredeneerde voorkeuren weerspiegelen. Een eventuele objectivisering ligt bij de identificatie van specifieke aspecten die verantwoordelijk zijn voor de kwaliteit, zodat individuele of niet-tekstuele impactfactoren geminimaliseerd worden. Elke vorm van evaluatie, ofwel op basis van een woordelijke beoordeling, een puntbeoordeling of een op beoordelingsmatrixen (Potočár 2016: 155-161) heeft praktische voor- en nadelen. In het geval van een toelatingsexamen moet een model echter het belangrijkste criterium volgen en dat is dat het de objectiviteit bij het beoordelen verhoogt.

Om de ideale evaluatievorm te vinden, die op de schriftelijke tekst als vertaalproduct gericht is, kunnen we ons voornamelijk baseren op theoretische uitgangspunten. Evaluatiemodellen combineren vaak onderscheidende soorten tekstbenaderingen. Zo kan de tekst worden aangepakt door een analytisch perspectief, dat de tekstprioriteiten op basis van de argumentatie classificeert, maar ook ten opzichte van holistische elementen, waar de focus op andere macro-tekstuele aspecten ligt. Op gelijkaardige manier kunnen de evaluatieresultaten een kwalitatieve beschrijving van de tekstkenmerken opleveren, of deze kan worden weerspiegeld in een heel kwantitatieve puntevaluatie. (Lee-Jahnke 2001: 260-265) Op deze manier vertegenwoordigen de referentie-evaluaties een specifieke vorm, die het algoritme instellen om de belangrijkste items in de vertaling te markeren, die "verantwoordelijk" zijn voor de algemene tekstkwaliteit. Een dominerend fenomeen op het gebied van evaluatiemodellen is een negatieve aanpak, die de fouten in de tekst benadrukt. Vanuit het perspectief van objectiviteit blijkt deze techniek problematisch te zijn, omdat hier het risico bestaat dat de beoordeling nog meer de subjectief geselecteerde aspecten onderstreept of hun gewicht classificeert op basis van zekere persoonlijke regels (Potočár 2017: 239).

De holistische (vaak ook de impressionistische) evaluatie gaat heel snel, is eenvoudig toepasbaar en geeft voldoende uitdrukking aan de kenmerken van de tekst als geheel (vgl. Al-Qinai 2000; Hansen 2006). Het fundamentele probleem is dat het van nature heel subjectief is, omdat de indrukken van de beoordelaar het meetinstrument zijn en "het blind vertrouwen" in zijn competenties het evaluatieobject naar andere niettekstuele niveaus verschuift. De analytische beoordeling daarentegen belooft een duidelijke objectievere weg op het microtekstuele vlak, die in samenhang met de juridische terminologie een heel belangrijke tekstnatuur reflecteert. De kwestie van de selectie van de geёvalueerde aspecten van de eerste stap, lijkt op dit punt nog belangrijker te zijn, 
aangezien de specifieke setting van elke fouttype en -graad een cruciale impact hebben op de eindresultaten (door het multipliceren van zwaarder gewogen punten en het soort fout). Ondanks grotere transparantie is deze aanpak nog steeds veel te subjectief vanwege de uitgebreide aanwezigheid van geïndividualiseerde voorkeuren. De taak van de evaluatiemethode is dan deze tekstprioriteiten effectief en onpartijdig te beredeneren, die op basis van de kennis van de tekst als parole ook de niet-tekstuele aspecten reflecteert.

\section{Een analytische focus op de kernelementen}

Deels geautomatiseerde beoordelingsmodellen, die zich op de referentiepunten baseren, kunnen zorgen voor meer objectiviteit en een verhoging van effectiviteit bij het organiseren van examens. De statistische PIE-methode (Segers \& Kockaert 2014) komt voort uit de theorie van Segers \& Van de Poel (2007). Deze zogenaamde ijkpuntmethode bestaat uit een analytische beoordeling van een relatief klein aantal geëvalueerde punten met dichotomische definitie van aanvaardbare oplossingen (d.w.z. goed/fout of vertaalkundig beter gedefinieerd: aanvaardbaar, niet-aanvaardbaar). Als eerste en belangrijkste stap van de beoordeling selecteert de beoordelaar in de brontekst de ijkpunten (ongeveer 10 per 200 woorden), die gedefinieerd worden als een term, zinsdeel, gesorteerde werkwoordfrase of een andere uitdrukking, die problemen bij het vertalen kan veroorzaken en waarbij de bereikte equivalentie belangrijk is voor de kwaliteit van de doeltekst. De methode vermijdt de negatieve aanpak bij de beoordeling, omdat deze niet te nauw focust op het vinden van fouten, maar het evalueert het vooraf gedefinieerde aantal aspecten dat essentieel wordt geacht voor het gegeven teksttype.

De huidige versie, de PIE-methode, vermijdt de subjectieve voorkeuren van de evaluator bij het selectieproces. Een belangrijk element om willekeurigheid van de selectie te voorkomen, is dat bij de beoordeling via statistische berekening de betrouwbaarheid van elk ijkpunt in twee stappen wordt berekend. In de eerste stap worden op basis van het succes van de geteste personen de ijkpunten afgeschrapt die statistisch veel te moeilijk of veel te gemakkelijk waren. In de tweede stap worden slechts die ijkpunten uitgekozen en diegene in de test weggelaten, waar de verschillen evident zijn tussen de twee statistische groepen vertalers, namelijk deze met de hoogste en met de laagste score. Door deze kalibratiemethode blijven bij de analytische beoordeling van de aanvaardbaarheid slechts betrouwbare referentiepunten over (Kockaert \& Segers 2016: 74-76.). Hoewel de methode zeer tijdsefficiënt kan zijn, in zoverre statistisch een groot aantal vertalingen bij de vertalingen tussen grote taalcombinaties wordt gecontroleerd (met Engels, Duits, Frans, Spaans, Nederlands, enz.), kan deze in kleinere getallen een nogal tijdrovende operatie worden, zonder significante verbetering op het gebied van objectiviteit. In de situatie van Slowaakse juridische vertalingen kunnen we namelijk aannemen dat een dergelijke statistische methode praktisch niet van toepassing is, aangezien de meeste taalcombinaties niet voldoende kandidaten opleveren en dus niet genoeg vertalingen om in te selecteren tijdens een enkele testronde. (Potočár 2017: 239-241) 


\section{De methode van de mate van progressieve consensus}

Het proces van selectie van de referentiepunten in de brontekst vormt ook de basis voor het opstellen van onze nieuwe methode. Deze houdt ook rekening met het lagere aantal geteste vertalingen met behulp van de berekening van de mate van consensus tussen de selecties van de verschillende beoordelaars. Heel cruciaal is dat de beoordelaars de elementen in de brontekst zelfstandig selecteren, dus zonder dat ze dit van elkaar weten. Het systeem van beoordeling van de geselecteerde elementen verloopt op een gelijkaardige manier als bij de oorspronkelijke ijkpuntmethode, maar wel met gebruik van het elimineren van de subjectieve factoren bij de selectie van de referentiepunten. Hier wordt dit doel bereikt door de progressieve puntevaluatie zoals we dit zien bij de statistische PIE-methode (Kockaert \& Segers 2016: 74). De individuele selectie zelf duurt slechts een paar minuten, omdat de beoordelaars alleen de geëvalueerde punten moeten markeren, die als de belangrijkste elementen voor de tekstkwaliteit beschouwd worden. Tegelijkertijd hebben de beoordelaars de mogelijkheid om eigen oplossingen of andere opmerkingen voor te stellen, om bij te dragen aan de discussie over de terminologische aanvaardbaarheid. Op die manier wordt een soort databank van ijkpunten gevormd, waarbij de consensusratio automatisch (her)berekend wordt en in een beoordelingsoutput wordt gezet. Praktisch toegepast betekent dit het volgende: hoe groter het aantal beoordelaars hetzelfde ijkpunt heeft geïdentificeerd als een sleutelelement, hoe groter het gewicht aan dit ijkpunt wordt toegekend.

Verder in het proces filtert de kalibratie die referentiepunten eruit, waar de bereikte consensusratio veel te laag is, zoals we kunnen zien in de tabel onderaan of uitgedrukt via de formule $\mathrm{MC}=\frac{\text { aantal evaluatoren- } 1}{3}$ (afgerond naar beneden). De minimale consensusdrempel verzekert dat er een adequaat aantal benaderde ijkpunten overblijft.

\begin{tabular}{|l|l|}
\hline Aantal beoordelaren & minimale consensusdrempel \\
\hline 2 beoordelaars & $\mathbf{1}$ \\
\hline 3 beoordelaars & $\mathbf{1}$ \\
\hline 4 beoordelaars & $\mathbf{2}$ \\
\hline 5 beoordelaars & $\mathbf{2}$ \\
\hline 6 beoordelaars & $\mathbf{2}$ \\
\hline 7 beoordelaars & $\mathbf{3}$ \\
\hline$\ldots$ & \\
\hline
\end{tabular}

Tabel 1: Minimale consensusdrempel

Deze maatregel wordt genomen om de effectiviteit maar ook de betrouwbaarheid te verhogen, aangezien de individuele factor bij het beoordeelde duidelijk wordt verminderd. De punten met hoge consensusratio vormen enkele kritische punten, die in tegenstelling tot subjectieve selectie van andere analytische referentiemethodes vanuit onafhankelijke invalshoeken worden gedefinieerd en automatisch via hoge puntentoekenning geaccentueerd worden. 
Een belangrijk aspect zijn de beoordelingsvaardigheden van de betrokken vertalers bij de selectie. Om de moeilijkheden in de uitgangstekst effectief te begrijpen en te kunnen markeren, is het niet noodzakelijk een beëdigd vertaler te zijn in de gegeven talencombinatie. Daarom onderzoekt de methode de diversiteit tussen de elementen, die door de beoordelaars met een ander beroepsprofiel (kwalificatie, ervaring en taalcombinaties) worden geselecteerd. Het onderscheidend vermogen van de evaluator de ijkpunten te selecteren wordt in de zogenaamde evaluatorrating uitgedrukt, die in de eindbeoordeling van de tekst gereflecteerd kan worden, om de individuele afwijkingen te minimaliseren. De evaluatorrating van een evaluator drukken we uit als gemiddelde consensusratio van "zijn” ijkpunten gemultipliceerd door de som consensusratio van "zijn” ijkpunten $\left(\Sigma_{\mathrm{i} 1+\mathrm{i} n * \mu_{\mathrm{i} 1+\mathrm{in}}}\right)$. Dit eindresultaat zorgt ervoor dat noch de evaluatoren die te veel, noch diegenen die te weinig ijkpunten geselecteerd hebben, begunstigd worden.

Het totale gewicht van één ijkpunt wordt geproduceerd door het vermenigvuldigen van de consensusratio en het gewicht van de evaluatorratings. Deze procedure legt automatisch minder nadruk op de ijkpunten, die geselecteerd zijn door hun lager aantal, maar ook minder succesvolle beoordelaars, en andersom voegt het principe een zwaarder gewicht toe aan de ijkpunten die gekozen zijn door meer en ook succesvolle (niet-geindividualiseerde) evaluatoren.

\begin{tabular}{|c|c|c|c|c|c|c|c|}
\hline $\begin{array}{l}\text { Evaluator } \rightarrow \\
\text { IJkpunt } \downarrow\end{array}$ & E1 & E2 & E 3 & E 4 & $\begin{array}{l}\text { Consensus } \\
\text { ratio }\end{array}$ & \begin{tabular}{|l|} 
Gewicht van \\
evaluatorra- \\
tings
\end{tabular} & Eindgewicht \\
\hline $\begin{array}{l}11 \\
12 \\
13 \\
14 \\
15 \\
\ldots\end{array}$ & $\begin{array}{l}\sqrt{ }(\text { ER } 1,7) \\
\sqrt{ }(\text { ER } 1,7) \\
\sqrt{ }(\text { ER } 1,7)\end{array}$ & $\begin{array}{l}\sqrt{ }(\text { ER 1,2) } \\
\sqrt{ }(\text { ER 1,2) } \\
\sqrt{ }(\text { ER 1,2) } \\
\sqrt{ }(\text { ER 1,2) }\end{array}$ & $\begin{array}{l}\sqrt{ }(\text { ER } 1,5) \\
\sqrt{ }(\text { ER } 1,5)\end{array}$ & $\begin{array}{l}\sqrt{ }(\operatorname{ER} 1,3) \\
\sqrt{ }(\operatorname{ER~} 1,3) \\
\sqrt{ }(\operatorname{ER~} 1,3)\end{array}$ & $\begin{array}{l}3 / 4 \\
2 / 4 \\
4 / 4 \\
2 / 4 \\
7 / 4\end{array}$ & $\begin{array}{l}4,5 \\
2,5 \\
5,8 \\
3,0 \\
7,2\end{array}$ & $\begin{array}{l}3,7(30 \%) \\
1,3(11 \%) \\
5,8(47 \%) \\
1,5(12 \%) \\
\theta, 7(0 \%)\end{array}$ \\
\hline $\begin{array}{l}\text { Evaluator } \\
\text { rating (ER) }\end{array}$ & 1,7 & 1,2 & 1,5 & 1,3 & & & $\begin{array}{l}\text { Max punten: } \\
12,3\end{array}$ \\
\hline
\end{tabular}

Tabel 2: Modelselectie in de brontekst

In het gegeven voorbeeld wordt het ijkpunt 3 door alle 4 evaluatoren geselecteerd. De som van alle evaluatorratings is 5,8 , waardoor dit ijkpunt met consensusratio 1 door zijn eindgewicht van $47 \%$ als een kritisch punt beschouwd kan worden. Dit betekent dat dit aspect door de vertaler goed moet vertaald worden. Hieruit volgt dat ijkpunt 3 dus cruciaal blijkt bij de beoordeling. Het eindgewichtsverschil tussen ijkpunten 2 en 4 ligt aan de kwaliteiten van de evaluatoren die het hebben gekozen. Het ijkpunt 5 wordt weggeschrapt, omdat het slechts door één beoordelaar werd geselecteerd, wat onder de minimale consensusdrempel ligt als we 4 evaluatoren ter beschikking hebben. Het uitgangspunt (en voor kleinere talen een enorm voordeel) is dat de methode al vanaf minimum 2 evaluatoren werkt. Bij een groter aantal beoordelaars daarentegen verhoogt de validiteit van de evaluatie, aangezien de vakgebonden vertaalproblemen gemeenschappelijk in de brontekst worden geïdentificeerd (Potočár: 243-244). 


\section{Verdere fasen van het beoordelingsproces}

Het bepalen van de aanvaardbaarheid van een vertaaloplossing kan, net zoals bij de statistische methoden, worden uitgevoerd met behulp van terminologiedatabases. De eindbeslissing kan ook uiteindelijk bij het oordeel van de commissie blijven liggen. In beide gevallen geldt dat het lagere aantal referentiepunten ruimte opent voor een diepere analyse om de aanvaardbaarheid van de vertaalalternatieven dichotomisch (ofwel dus correct, of niet correct) te bepalen. De grotere tijdinvestering in de voorbereidingsfase werpt zijn vruchten af in de daaropvolgende fases: De commissie moet overeenkomen of de vertalingen van nogal weinig ijkpunten acceptabel of niet acceptabel zijn. De berekening van de eindresultaten verloopt op zich automatisch, omdat de waarden op basis van de inputgegevens automatisch de vertaalkwaliteit in percentages weergeven.

\section{Conclusie in de validiteit van de evaluatiemethode}

De voorgestelde evaluatiemethode kan, net als de tekst, een object van beoordeling worden door het definiëren van de factoren die de objectiviteit verbeteren. Hoewel de selectie van de geëvalueerde elementen zonder tussenkomst van een individuele menselijke factor kan plaatsvinden, blijft de objectiviteitsdoelstelling een omstreden onderwerp, omdat de gepresenteerde formulieren op zeker gedefinieerde berekeningsformules respectievelijk op een pluralistische subjectiviteit berusten. Vanuit dit oogpunt lijkt de objectiviteit als een hoofddoel van het beoordelingsmodel een onhaalbaar ideaal te blijven. De vermindering van persoonlijke prioriteiten kan de validiteit van de beoordeling vooral in de situatie van de kleinere taalcombinaties aanzienlijk verhogen, waarbij de beoordeling heel sterk wordt beïnvloed door de subjectieve indrukken van een specifieke beoordelaar of een andere vertaler. Op basis van meerdere geïndividualiseerde waarden en evaluatieperspectieven wordt dan het zwaartepunt van de individuele competentiekwesties naar het tekstproductieproces verschoven. (Potočár 2017: 246-247). Ook al vertrouwt de methode nog steeds op menselijke input en kan ze in tegenstelling tot de PIE-methode niet volledig geautomatiseerd verlopen, toch levert ze betrouwbare referentiepunten op, die een beeld geven over de kwaliteit van de vertaling, maar ook over de bronteksten en de evaluatoren, wat relevant is voor een effectieve, analytische en op de belangrijkste aspecten van de tekst geconcentreerde evaluatie.

\section{Bronnen}

Al-Qinai, Jamal. (2000): Translation Quality Assessment. Strategies, Parametres and Procedures. In: Meta: Translators' Journal, 41(155), p. 497-519.

Catford, John C. (1978): A Linguistic Theory of Translation. Oxford: University Press.

Richtlijn 2010/64/EU van het Europese Parlement en Commissie. < http://eur-lex.europa.eu/

LexUriServ/LexUriServ.do?uri=OJ:L:2010:280:0001:0007:en:PDF> 
EULITA. (2013): Assises de la Justice. Preliminary Input to the Discussion: Completing the European Area of Justice - Tell us what comes next. <http:///ec.europa.eu/justice/events/assisesjustice-2013/files/contributions/25.eulita_assisdelajustice_en.pdf>

Hansen, Gyde (2006): Erfolgreich Übersetzen. Entdecken und Beheben von Störquellen. Tübingen: Narr.

Hertog, Erik; Vanden Bosch, Yolanda (2001): Access to Justice across Language. In: Erik Hertog (ed.): Aequitas_Acces to Justice across Language and Culture in the EU. Antwerpen: Lessius Hogeschool. <www.legalinttrans.info/Aequintas.pdf>

Hrehovčík, Teodor (2006): Prekladatel'ské minimum. Bratislava: Iris.

Kockaert, Hendrik; Segers, Winibert (2014): Evaluation de la traduction: la méthode PIE (Preselected Items Evaluation). In: Turjuman, 23(2), p. 232-250.

Lee-Jahnke, Hannelore (2001): Aspects pédagogiques de l'évaluation des traduction. In: Meta: Translators' Journal 46, 46(2), p. 258-271.

Orlando, Danielle (2015): The Trials of Legal Translation Competence: Triangulating processes and products of translators vs. Lawyers. Trieste: Università degli Studi di Trieste.

Potočár, Milan (2016): Juridische vertaling tussen kleinere talen evalueren: Kwaliteitscriteria voor juridische vertaling onderdeel van het onderzoeksproject TransIus. In: Roczniki Humanistyczne, 64(5), p. 155-164.

Potočár, Milan (2017): Von der Evaluierung zum Qualitätsmanagement. In J. Rakšányiová et al. [et al.], Quo vadis, Rechtsübersetzung?. Bratislava: Univerzita Komenského v Bratislave, p. 221-252.

Prieto Ramos, Fernando. (2011): Developing Legal Translation Competence: An Integrative Process-Oriented Approach. In: Comparative Legilinguistics - International Journal for Legal Communication, 5, p. 7-21.

Segers, Winibert; Kockaert, Hendrik (2016): Can Subjectivity be Avoided In: Translation Evaluation? In: Marcel Thelen / Gys-Walt Van Egdom / Dirk Verbeeck / Łukasz Bogucki / Barbara Lewandowska-Tomaszczyk (ed.): Translation and Meaning. vol. 1, 41. Łódź: Peter Lang, p.69-78.

Segers, Winibert; Van den Poel, Chris (2007): Vertalingen objectief evalueren. Matrices en ijkpunten. Leuven / Voorburg: Acco.

Štefková, Markéta (2013a): Aktuálne výzvy výskumu súdneho prekladu v slovenskom kontekste. Prezentácia projektu TRANSIUS - Od konvencií k normám prekladu v právnom diskurze. In: Zuzana Guldanová (ed.): Konteksty súdneho tlmočenia a preklad 2. Bratislava: Univerzita Komenského v Bratislave, p. 124-134.

Štefková, Markéta (2013b): Právny tekst v preklade. Translatologické aspekty právnej komunikácie v málo rozšírených jazykoch. Bratislava: Iura Edition.

www1. (2017): Jednotný automatizovaný systém právnych informácií. http://jaspi.justice.gov.sk/

Mgr. Milan Potočár, Ph.D. / potočármilan@gmail.com

Lic. Benjamin Bossaert / benjamin.bossaert@uniba.sk

Univerzita Komenského, Filozofická fakulta, Katedra germanistiky, nederlandistiky a škandinavistiky Gondova 2, 81499 Bratislava, SK

This work can be used in accordance with the Creative Commons BY-SA 4.0 International license terms and conditions (https://creativecommons.org/licenses/by-sa/4.0/legalcode). This does not apply to works or elements (such as image or photographs) that are used in the work under a contractual license or exception or limitation to relevant rights 
